\title{
Seed Mediated One-pot Growth of Versatile Heterogeneous Upconversion Nanocrystals for Multimodal Bioimaging
}

\author{
Shihui Wen ${ }^{1,3}$, Du Li ${ }^{1,2,3,4}$, Deming Liu ${ }^{1,2,3}$, Xiaoxue $\mathrm{Xu}^{1,2,3}$, Yi Du ${ }^{5}$, David R. G. Mitchell ${ }^{6}$, \\ Bingyang Shi ${ }^{3,7}$, Xiangyang $\mathrm{Shi}^{4}$, Dayong Jin ${ }^{1,2,3 *}$
}

${ }^{1}$ Institute for Biomedical Materials and Devices, Faculty of Science, University of Technology Sydney, NSW, 2007, Australia; ${ }^{2}$ ARC Research Hub for Integrated Device for End-user Analysis at Low-levels (IDEAL), Faculty of Science, University of Technology, Sydney, New South Wales 2007, Australia; ${ }^{3}$ Advanced Cytometry Labs, ARC Centre of Excellence for Nanoscale BioPhotonics, Macquarie University, Sydney, NSW, 2109, Australia; ${ }^{4}$ State Key Laboratory for Modification of Chemical Fibers and Polymer Materials, College of Materials Science and Engineering, Donghua University, Shanghai 201620, People's Republic of China; ${ }^{5}$ Institute for Superconducting and Electronic Materials, Innovation Campus, University of Wollongong, NSW, 2522, Australia; ${ }^{6}$ Australian Institute for Innovative Materials (AIIM), Innovation Campus, University of Wollongong, North Wollongong, NSW, 2522, Australia; ${ }^{7}$ Faculty of Medicine \& Health Sciences, Macquarie University, Sydney, NSW, 2109, Australia

*Corresponding author: dayong.jin@uts.edu.au (D. Jin)

\begin{abstract}
:
The rapid development of a variety of molecular contrast agents makes the multimodality bioimaging highly attractive towards higher resolution, more sensitive, informative diagnosis. The key lies in the development of facile material synthesis that allows the integration of multiple contrast agents, ideally in a way that each of the components should be logically assembled to maximize their performances. Here, we report the one-pot programmable growth of multifunctional heterogeneous nanocrystal with tunable size, shape, composition, and properties. We demonstrated a facile one-pot hot-injection method to enable the highly selectively controlled growth of different sodium lanthanide fluoride nanomaterials in either longitudinal or transversal directions with atomic scale precision. This technique allows the upconversion luminescence signal, MRI signal and x-ray signal logically integrated and optimized within one single versatile nanoplatform for multimode bioimaging. These findings suggest that the facile strategy developed here have the promising to get the desired heterogeneous nanocrystals as an all-in-one contrast agent for integrated and self-correlative multimodal bioimaging.
\end{abstract}

\section{KEYWORDS:}

Upconversion nanocrystals, one-pot synthesis, heterogeneous growth, partitioned doping, multimode imaging

\section{INTRODUCTION}

The rapid development of the molecular imaging technology makes the multimodality imaging is possible to circumvent the limitations of single imaging modes and provide more sensitive and accurate diagnosis. ${ }^{1,2}$ For example, multimodality single-photon emission computed tomography (SPECT)/X-ray computed tomography (CT) imaging technology was introduced in 1977 and widely used in clinical diagnosis. However, the performance of the multimode imaging is strongly determined by the usage of the contrast agent, apart from the improvement in the instrument and methodology. ${ }^{3-5}$ Therefore, the development of flexible multimodal platform which allows selection of the imaging modality to be used has evoked considerable interest. ${ }^{1,9-9}$

SPIE BioPhotonics Australasia, edited by Mark R. Hutchinson, Ewa M. Goldys, Proc. of SPIE Vol. 10013, 1001315 - (C) 2016 SPIE · CCC code: 0277-786X/16/\$18 - doi: 10.1117/12.2245172 
For multimodal contrast agents design, lanthanide doped upconverting nanoparticles (UCNPs) have created tremendous excitements own to their incomparable advantages such as improved deep tissue penetration and zero auto-fluorescence. ${ }^{9-16}$ Apart from these excellent optical imaging applications, UCNPs could also be used as magnetic resonance (MR) and CT contrast agent due to the high attenuation and magnetic properties of some lanthanide ions. In particular, for MR imaging, $\mathrm{NaGdF}_{4}{ }^{-}$or $\mathrm{KMnF}_{3}$-based $T_{1} \mathrm{MR}$ contrast agents and $\mathrm{NaDyF}_{4}$-based $T_{2} \mathrm{MR}$ contrast agents have been designed for imaging applications. ${ }^{17,}{ }^{18}$ For CT imaging applications, all the lanthanide elements have the higher attenuation than the clinical used Iodine-based CT contrast agents. Therefore, host of multifunctional UCNPs were successfully formed for dual/triplet bioimaging, which makes it possible to get complementary in vivo information from different imaging modalities with a single administration. Even much efforts have been dedicated, most of the formed agents are just the "mixture" of the different imaging agent for multimodal imaging. ${ }^{9}$ To fulfill the advantage of the different imaging modals, it is essence to programmable design and fabricate the integrated agent with different agent sitting in their advantage placement with atomic scale precision. For instance, $\mathrm{NaGdF}_{4}$ should be put on the surface of the final particles due to its the surface Gd ions are the major contributors to the relaxivity enhancement, while $\mathrm{NaYF}_{4}, \mathrm{Yb}$,Er should be in the central of the particle to enhance the luminescence. Also, Dy should be away from the $\mathrm{Yb}$ or Er due to its quench effect, for $\mathrm{CT}$ imaging Lu have the highest attenuation and could be put in any place. However, the development of a programmable diversity of nanomaterials with the desired functionalities and performance has always been the challenge for chemists and material scientists.

In this present study, we developed a synthesis strategy capable of engineering the architecture of heterogeneous UCNPs through rational and independent programming of every architecture-determining element. The shape, size and the element spatial arrangement could be well controlled. Through facile one-pot hot-injection method, programmable heterogeneous nanocrystals (including nanorod, nanodumbbell, and nanoring-coated-dumbbell) were formed via controlled selectively growth of different sodium lanthanide fluoride nanocrystals in site and direction. The formed partitioned heterogeneous nanocrystals afford their uses as nanoplatform for multimode CT/MR/UCL imaging to fulfil their advantages in biomedicine.

\section{EXPERIMENTAL SECTION}

UCNPs had been synthesized according to our previously reported method. ${ }^{11,19}$ The longitudinal growth of $\mathrm{NaREF}_{4}$ onto the core of $\mathrm{NaYF}_{4}: \mathrm{Yb}, \mathrm{Er} \mathrm{NCs}$ was conducted via a successive layer-by-layer hot-injection protocol. Firstly, shell precursors were prepared. $1.0 \mathrm{mmol} \mathrm{YCl}_{3} 6 \mathrm{H}_{2} \mathrm{O}$ were added to a $50 \mathrm{~mL}$ flask containing oleic acid $(\mathrm{OA}, 6.5 \mathrm{~mL})$ and 1-octadecene (ODE, $15 \mathrm{~mL}$ ). The mixture was heated to $170{ }^{\circ} \mathrm{C}$ under argon for $30 \mathrm{~min}$ to obtain a clear solution and then cooled down to about $50{ }^{\circ} \mathrm{C}$, followed by the addition of $5 \mathrm{~mL}$ methanol solution of $\mathrm{NH}_{4} \mathrm{~F}(4.0 \mathrm{mmol})$ and $\mathrm{NaOH}$ $(2.5 \mathrm{mmol})$ and $3 \mathrm{~mL}$ methanol solution of $\mathrm{KOH}(2.0 \mathrm{mmol})$. After stirring for $30 \mathrm{~min}$, the solution was heated to 80 ${ }^{\circ} \mathrm{C}$ under argon for $20 \mathrm{~min}$ to remove methanol, and then the solution was further heated to $150{ }^{\circ} \mathrm{C}$ for another $30 \mathrm{~min}$. Finally, the reaction solution was cooled down to room temperature and labeled as $\mathrm{NaYF}_{4}$ shell precursors. Similarly,

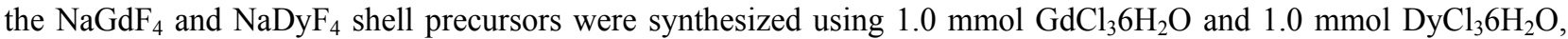
instead of $\mathrm{YCl}_{3} 6 \mathrm{H}_{2} \mathrm{O}$. For the longitudinal growth of $\mathrm{NaYF}_{4}, 0.2 \mathrm{mmol} \mathrm{NaYF}_{4}: \mathrm{Yb}$,Er core particles were added to a 50 $\mathrm{mL}$ flask containing $3 \mathrm{~mL} \mathrm{OA,} 7 \mathrm{~mL}$ ODE, $69 \mathrm{mg} \mathrm{NaOH}$, and $77 \mathrm{mg} \mathrm{KOH}$. The mixture was heated to $170{ }^{\circ} \mathrm{C}$ under argon for $30 \mathrm{~min}$, and then the solution was further heated to $310^{\circ} \mathrm{C}$. After that, $0.5 \mathrm{~mL}$ of $\mathrm{NaYF}_{4}$ shell precursors were immediately injected into the reaction mixture and ripened at $310^{\circ} \mathrm{C}$ for $5 \mathrm{~min}$ followed by the same injection and ripening cycles for 20 times. Finally, the reaction solution was cooled down to room temperature and the formed nanorods were purified according to the procedures used for the purification of $\mathrm{NaYF}_{4}: \mathrm{Yb}$,Er core particles.

For the nanodumbbell synthesis, the $\mathrm{NaYF}_{4}: \mathrm{Yb}, \mathrm{Er} @ \mathrm{NaLuF}_{4} @ \mathrm{NaDyF}_{4}$ rods were first formed according to method 2.3. Then $0.15 \mathrm{mmol} \mathrm{GdCl}_{3}$ were added to a $50 \mathrm{~mL}$ flask with $6 \mathrm{~mL} \mathrm{OA}$ and $6 \mathrm{~mL}$ ODE. The mixture was heated to 170 ${ }^{\circ} \mathrm{C}$ under argon for $30 \mathrm{~min}$ to obtain a clear solution and cooled down to about $50{ }^{\circ} \mathrm{C}$, followed by the addition of 4 $\mathrm{mL}$ methanol solution of $\mathrm{NH}_{4} \mathrm{~F}(0.6 \mathrm{mmol}), \mathrm{NaOH}(0.15 \mathrm{mmol})$ and $\mathrm{KOH}(0.12 \mathrm{mmol})$. After stirring for $30 \mathrm{~min}$, the formed $\mathrm{NaYF}_{4}: \mathrm{Yb}, \mathrm{Er} @ \mathrm{NaLuF}_{4} @ \mathrm{NaDyF}_{4}$ rods $(0.05 \mathrm{mmol}$ in cyclohexane) were added and the solution was heated to $80{ }^{\circ} \mathrm{C}$ under argon for $20 \mathrm{~min}$ to remove methanol and cyclohexane, and then the solution was further heated to 310 ${ }^{\circ} \mathrm{C}$ for another $90 \mathrm{~min}$. Finally, the reaction solution was cooled down to room temperature and the formed nanoplate were purified according to the procedures used for the purification of $\mathrm{NaYF}_{4}: \mathrm{Yb}, \mathrm{Er}$ core particles. In terms of the nanoring-coated-nanodumbbell synthesis, the methods was similar with the nanodumbbell synthesis, except the 0.1875 mmol of $\mathrm{NaOH}$ was used and without the addition of $\mathrm{KOH}$. 


\section{RESULTS AND DISCUSSION}

The UCNPs nanostructure design for multimodal imaging is depicted in Figure 1. A bamboo structure nanoparticle platform was employed to host upconverting luminescence, T2-based MR imaging, T1-based MR imaging as well as CT imaging contrast agents at different parts. A facile seed-mediated one-pot hot-inject method was used to synthesis our versatile heterogeneous materials through controlled longitudinal heterogeneous growth of appropriate lanthanide ions. As a result, incompatible optical, MR, and CT imaging agents can be programmable engineered for flexible and efficient multimodal imaging applications.

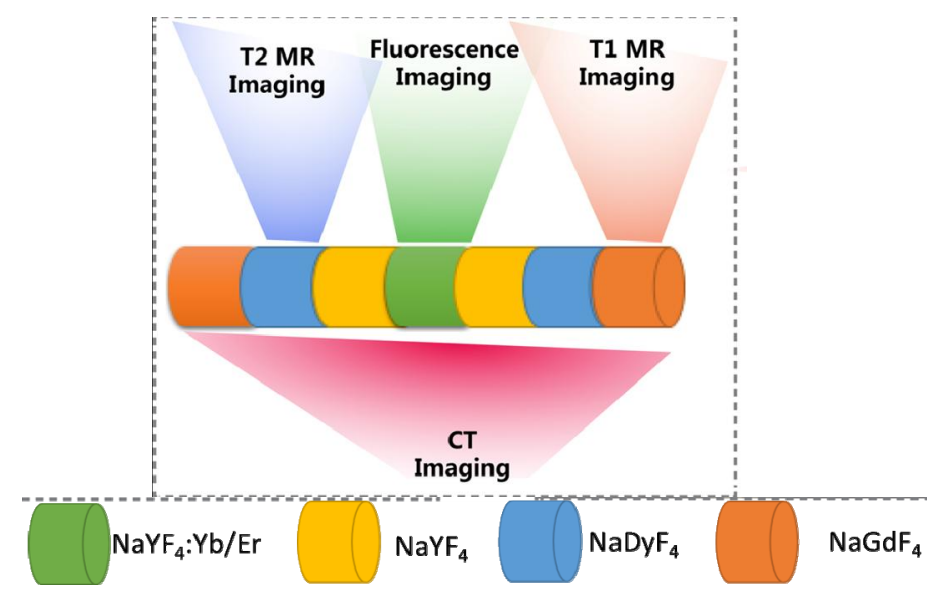

Figure 1. Schematic structure of the designed UCNPs through longitudinal epitaxial growth for multimode imaging

As a proof-of-concept experiment, we employed a seven-section $\mathrm{NaYF}_{4}, \mathrm{Yb}_{2} \mathrm{Er}_{-} \mathrm{NaYF}_{4}-\mathrm{NaDyF}_{4}-\mathrm{NaGdF}_{4}$ nanocrystals in a bamboo shape by longitudinal controlled growth. $\mathrm{NaYF}_{4}, \mathrm{Yb}, \mathrm{Er}$ in the core site was employed for luminescence imaging $\mathrm{Yb}^{3+}$ and $\mathrm{Er}^{3+}$ harvest the NIR excitations. Then, a section of $\mathrm{NaYF}_{4}$ was chosen to separate $\mathrm{Yb}^{3+} / \mathrm{Er}^{3+}$ with $\mathrm{Dy}^{3+}$ (T2-based MR imaging) to avoid the quenching by cross-relaxation. Finally, NaGdF $4 \mathrm{Was}$ chosen as the outer parts for better T1-based MR contrast effect due to its the surface $\mathrm{Gd}^{3+}$ are the major contributors to the imaging enhancement.

The seed nanoparticle $\left(\mathrm{NaYF}_{4}: 20 \% \mathrm{Yb}, 2 \% \mathrm{Er}\right)$ with the diameter around $25 \mathrm{~nm}$ (Figure 2a) had been first synthesized for the further controlled growth. Transmission electron microscopy (TEM) micrographs (Figure 1b-d) confirmed that the epitaxial growth of shells in the longitudinal direction of the core. After the $\mathrm{NaYF}_{4}$ controlled growth, apparent rod-like shape structures with the length of $42 \mathrm{~nm}$ were obtained, different from the core with the quasi-sphere morphology. Further, the length of nanorods increased to 57 and $70 \mathrm{~nm}$ after the further growth of $\mathrm{NaDyF}_{4}$ and $\mathrm{NaGdF}_{4}$, respectively. It is notable that the width of the nanocrystals did not show any apparent changes and remained at around $25 \mathrm{~nm}$ for the whole reaction process. The elemental mapping analysis shows the elemental distribution of $\mathrm{Gd}, \mathrm{Dy}, \mathrm{Y}, \mathrm{Yb}, \mathrm{Na}$, and $\mathrm{F}$ of the formed nanorods (Figure 2e), which are very consistent with the our designed structure. 

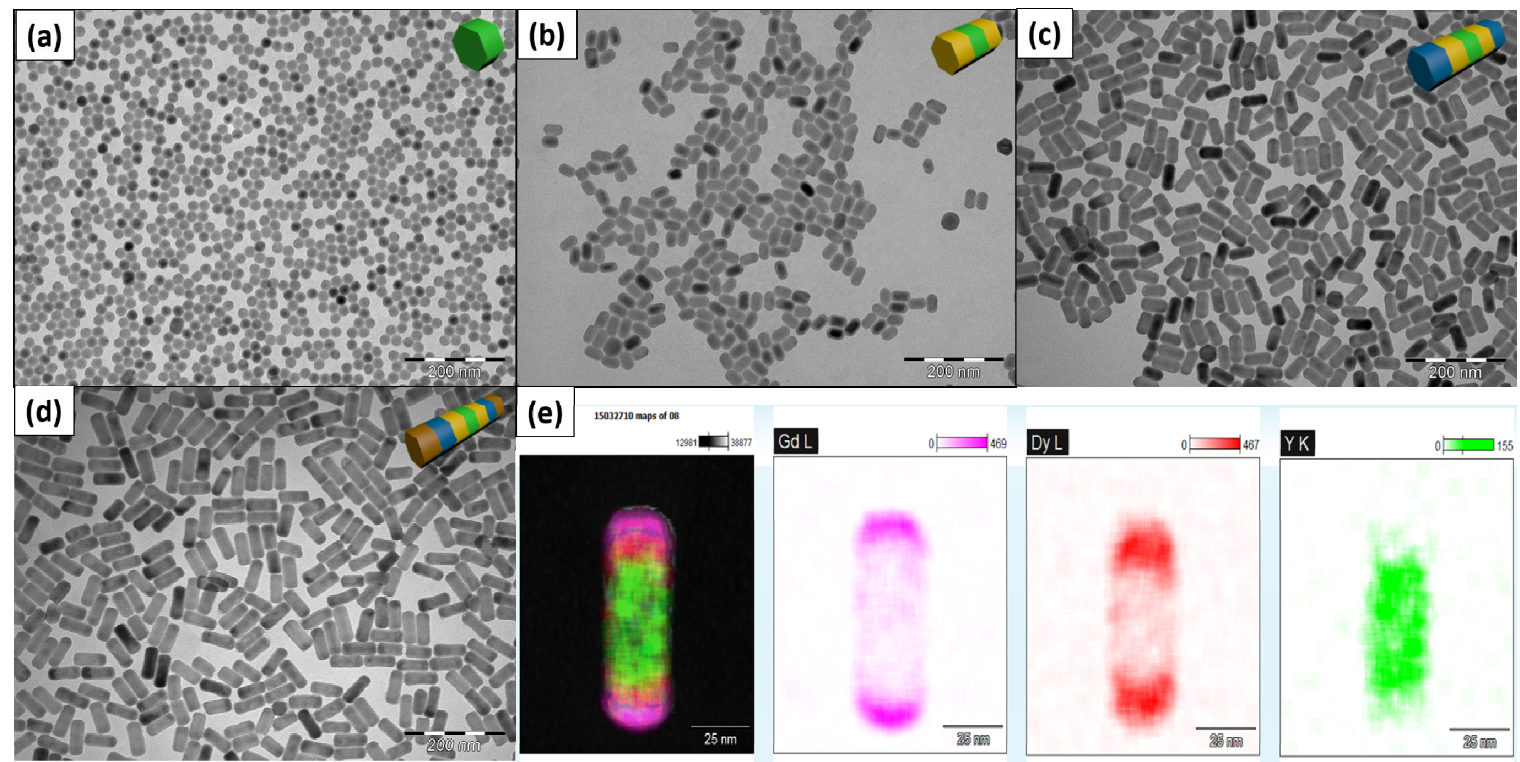

(e)
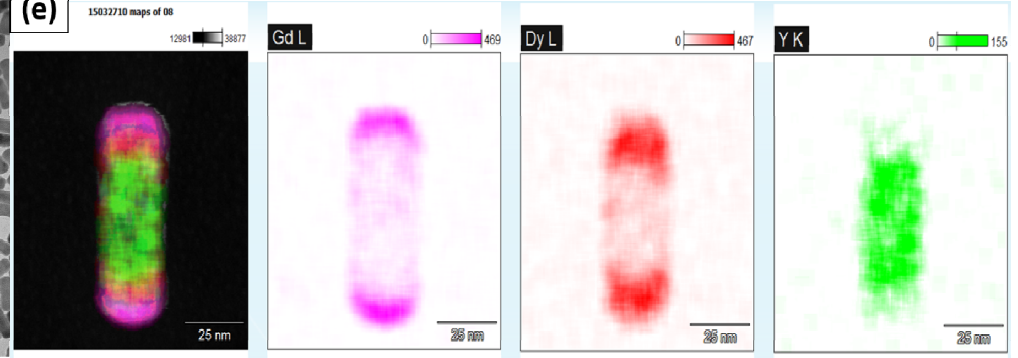

Figure 2. TEM images of the UCNPs nanospheres (a) and nanorods (b-d) with different aspect ratio and different materials through longitudinal epitaxial growth. (a) UCNPs core nanospheres $\mathrm{NaYF}_{4}: \mathrm{Yb}, \mathrm{Er}$; (b) three-section $\mathrm{NaYF}_{4}: \mathrm{Yb}_{2} \mathrm{Er}_{-\mathrm{NaYF}}$ nanorods by growth of $\mathrm{NaYF}_{4}$; (c) five-section $\mathrm{NaYF}_{4}: \mathrm{Yb}, \mathrm{Er}-\mathrm{NaYF}_{4}-\mathrm{NaDyF}_{4}$ nanorods by growth of $\mathrm{NaDyF}_{4}$; (d) seven-section $\mathrm{NaYF}_{4}: \mathrm{Yb}, \mathrm{Er}-\mathrm{NaYF}_{4}-\mathrm{NaDyF}_{4}-\mathrm{NaGdF}_{4}$ nanorods by growth of $\mathrm{NaGdF}_{4}$; (e) HAADF-STEM image with elemental mapping of the seven-section $\mathrm{NaYF}_{4}: \mathrm{Yb}, \mathrm{Er}-\mathrm{NaYF}_{4}-\mathrm{NaDyF}_{4}-\mathrm{NaGdF}_{4}$ nanorod.

To confirm the feasibility of the developed methods, we also synthesized seven-section $\mathrm{NaYF}_{4}, \mathrm{Yb}, \mathrm{Er}-\mathrm{NaYF}_{4}-\mathrm{NaGdF}_{4}-\mathrm{NaDyF}_{4}$ nanorods using same methods just change the addition order of $\mathrm{NaDyF}_{4}$ and $\mathrm{NaGdF}_{4}$. The results show that the growth behavior of $\mathrm{NaYF}_{4}, \mathrm{Yb}, \mathrm{Er}-\mathrm{NaYF}_{4}-\mathrm{NaGdF}_{4}-\mathrm{NaDyF}_{4}$ nanorods is similar with that of $\mathrm{NaYF}_{4}, \mathrm{Yb}, \mathrm{Er}-\mathrm{NaYF}_{4}-\mathrm{NaDyF}_{4}-\mathrm{NaGdF}_{4}$ nanorods, which means the order of the element could be optional change depend on our design. Moreover, the nanodumbbell (Figure 3d) and nanoring-coated-dumbbell (Figure 3e) nanocrystals could be synthesized through changing the amount of the $\mathrm{NaOH}$ and $\mathrm{KOH}$ in the reaction system. These results means the mono-disperse nanorods with high aspect ratio or different element doping can be facile synthesized by the seed-mediated epitaxial growth in a high concentration of oleate ions and the aid of $\mathrm{KOH}$. This is due to the aid of high concentration of $\mathrm{NaOH}$ or $\mathrm{KOH}$ in the reaction oleate ions can passivate effectively the side surfaces (100) (010) of nanorods and so grow very long homogeneous or heterogamous nanocrystals with the control. 


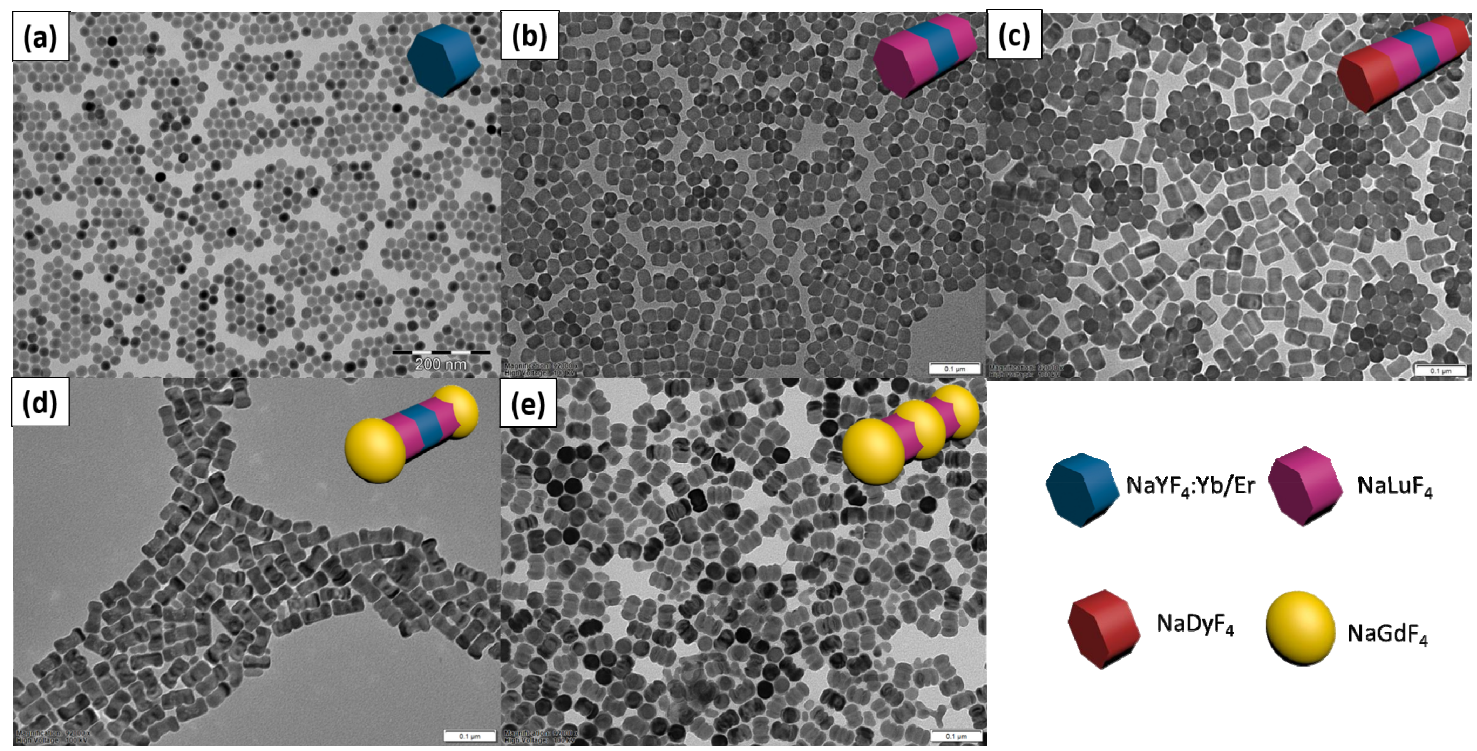

Figure 3. TEM images of the UCNPs nanospheres (a), nanorods (b, c), nanodumbbell (d) and nanoring-coated-dumbbells (e) with different aspect ratio and different materials through longitudinal and transversal epitaxial growth.

Before the multimode imaging application of the developed nanoring-coated-dumbbells, their cytotoxicity was first evaluated by the standard MTT viability assay. As shown in figure $4 \mathrm{a}$, no significant cytotoxicity of the nanoring-coated-dumbbells is discovered even at the concentration of the particles as high as $80 \mathrm{ug} / \mathrm{mL}^{-1}$, when compared to the cells treated with PBS. The good cytocompatibility of the nanocrystals is crucial for their further bioimaging applications. To confirm the multimode imaging ability of the formed nanoring-coated-dumbbells, we did the in vivo MR/CT/UCL imaging of a xenografted tumor model. As shown in figure $4 \mathrm{~b}$, the tumor region shows a high contrast signal to the background in all the four imaging modes after intratumoral injection compared with that before the injection. These results suggest that the acquired nanoring-coated-dumbbells have a promising capability for in vivo multimode bioimaging.
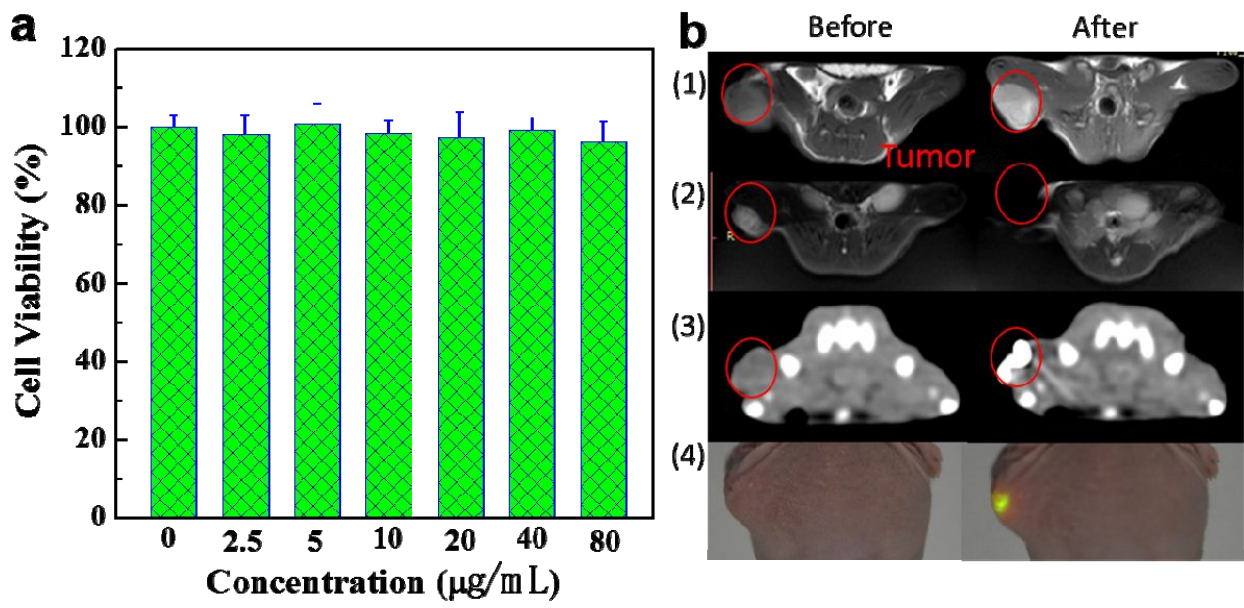

Figure 4. Cell viability study and in vivo bioimaging. (a) MTT assay of the viability of SKOV-3 cells after treatment with nanoring-coated-dumbbells at different concentrations for 24 h; (b) In vivo MR T1 (1), MR T2 (2), CT (3), and UCL (4) images of the xenografts SKOV-3 tumor model before and after injection of the multifunctional UCNPs. 


\section{CONCLUSIONS}

To conclude, we develop a facile seed mediated one-pot hot-injection method to build the multifunctional heterogeneous nanocrystal for multimode bioimaging. The method enables the highly selectively controlled growth of different sodium lanthanide fluoride in either longitudinal or transversal directions. Through optimizing different imaging element within one versatile nanoplatform, the formed multifunctional nanoring-coated-dumbbells shows the excellent MR/CT/UCL imaging ability. Due to the easy surface functionalization of the nanocrystals, it is expected that multifunctional nanoring-coated-dumbbells may be developed as a versatile platform for targeted imaging as well as the drug delivery.

\section{REFERENCES}

[1] Louie, A. Y. "Multimodality Imaging Probes: Design and Challenges," Chem. Rev. Papers 110(5), 3146-3195 (2010).

[2] Lee, D.-E., Koo, H., Sun, I.-C., Ryu, J. H., Kim, K., and Kwon, I. C. "Multifunctional nanoparticles for multimodal imaging and theragnosis," Chem. Soc. Rev. Papers 41(7), 2656-2672 (2012).

[3] Zarschler, K., Rocks, L., Licciardello, N., Boselli, L., Polo, E., Garcia, K. P., De Cola, L., Stephan, H., and Dawson, K. A. "Ultrasmall inorganic nanoparticles: State-of-the-art and perspectives for biomedical applications," Nanomedicine: Nanotechnology, Biology and Medicine. Papers 12(6), 1663-1701 (2016).

[4] Wen, S., Li, K., Cai, H., Chen, Q., Shen, M., Huang, Y., Peng, C., Hou, W., Zhu, M., Zhang, G., and Shi, X. "Multifunctional dendrimer-entrapped gold nanoparticles for dual mode CT/MR imaging applications," Biomaterials. Papers 34(5), 1570-1580 (2013).

[5] Chen, Q., Li, K., Wen, S., Liu, H., Peng, C., Cai, H., Shen, M., Zhang, G., and Shi, X. "Targeted CT/MR dual mode imaging of tumors using multifunctional dendrimer-entrapped gold nanoparticles," Biomaterials. Papers 34(21), 5200-5209 (2013).

[6] Weissleder, R. "Molecular imaging in cancer," Science. Papers 312(5777), 1168-1171 (2006).

[7] Alric, C., Taleb, J., Le Duc, G., Mandon, C., Billotey, C., Le Meur-Herland, A., Brochard, T., Vocanson, F., Janier, M., Perriat, P., Roux, S., and Tillement, O. "Gadolinium chelate coated gold nanoparticles as contrast agents for both X-ray computed tomography and magnetic resonance imaging," J. Am. Chem. Soc. Papers 130(18), 5908-5915 (2008).

[8] Baptista, P., Pereira, E., Eaton, P., Doria, G., Miranda, A., Gomes, I., Quaresma, P., and Franco, R. "Gold nanoparticles for the development of clinical diagnosis methods," Anal. Bioanal. Chem. Papers 391(3), 943-950 (2008).

[9] Li, X., Zhang, F., and Zhao, D. "Lab on upconversion nanoparticles: optical properties and applications engineering via designed nanostructure," Chemical Society Reviews. Papers 44(6), 1346-1378 (2015).

[10] Gai, S., Li, C., Yang, P., and Lin, J. "Recent Progress in Rare Earth Micro/Nanocrystals: Soft Chemical Synthesis, Luminescent Properties, and Biomedical Applications," Chemical Reviews. Papers 114(4), 2343-2389 (2014).

[11] Zhao, J., Lu, Z., Yin, Y., McRae, C., Piper, J. A., Dawes, J. M., Jin, D., and Goldys, E. M. "Upconversion luminescence with tunable lifetime in NaYF4:Yb,Er nanocrystals: role of nanocrystal size," Nanoscale. Papers 5(3), 944-952 (2013).

[12] Zhang, Y., Zhang, L., Deng, R., Tian, J., Zong, Y., Jin, D., and Liu, X. "Multicolor Barcoding in a Single Upconversion Crystal," Journal of the American Chemical Society. Papers 136(13), 4893-4896 (2014). 
[13] Zhou, B., Shi, B., Jin, D., and Liu, X. "Controlling upconversion nanocrystals for emerging applications," Nat Nano. Papers 10(11), 924-936 (2015).

[14] Lu, Y., Lu, J., Zhao, J., Cusido, J., Raymo, F. M., Yuan, J., Yang, S., Leif, R. C., Huo, Y., Piper, J. A., Paul Robinson, J., Goldys, E. M., and Jin, D. "On-the-fly decoding luminescence lifetimes in the microsecond region for lanthanide-encoded suspension arrays," Nature Communications. Papers 5(3741 (2014).

[15] Lu, Y., Zhao, J., Zhang, R., Liu, Y., Liu, D., Goldys, E. M., Yang, X., Xi, P., Sunna, A., Lu, J., Shi, Y., Leif, R. C., Huo, Y., Shen, J., Piper, J. A., Robinson, J. P., and Jin, D. "Tunable lifetime multiplexing using luminescent nanocrystals," Nat Photon. Papers 8(1), 32-36 (2014).

[16] Zhao, J., Jin, D., Schartner, E. P., Lu, Y., Liu, Y., Zvyagin, A. V., Zhang, L., Dawes, J. M., Xi, P., Piper, J. A., Goldys, E. M., and Monro, T. M. "Single-nanocrystal sensitivity achieved by enhanced upconversion luminescence," Nat Nano. Papers 8(10), 729-734 (2013).

[17] Johnson, N. J. J., Oakden, W., Stanisz, G. J., Scott Prosser, R., and van Veggel, F. C. J. M. "Size-Tunable, Ultrasmall NaGdF4 Nanoparticles: Insights into Their T1 MRI Contrast Enhancement," Chemistry of Materials. Papers 23(16), 3714-3722 (2011).

[18] Das, G. K., Johnson, N. J. J., Cramen, J., Blasiak, B., Latta, P., Tomanek, B., and van Veggel, F. C. J. M. "NaDyF4 Nanoparticles as T2 Contrast Agents for Ultrahigh Field Magnetic Resonance Imaging," The Journal of Physical Chemistry Letters. Papers 3(4), 524-529 (2012).

[19] Liu, D., Xu, X., Du, Y., Qin, X., Zhang, Y., Ma, C., Wen, S., Ren, W., Goldys, E. M., Piper, J. A., Dou, S., Liu, $\mathrm{X}$., and Jin, D. "Three-dimensional controlled growth of monodisperse sub-50 nm heterogeneous nanocrystals," Nature Communications. Papers 7(10254 (2016). 